\title{
Maternal Hypotension During Spinal Anesthesia for Cesarean Delivery
}

\author{
Ioanna Mavridou • Adrienne Stewart • \\ Roshan Fernando
}

Published online: 14 September 2013

(c) Springer Science + Business Media New York 2013

\begin{abstract}
Spinal hypotension is a common problem encountered by anesthesiologists when providing spinal anesthesia (SA) for cesarean delivery (CD). Recent research involving use of noninvasive and minimally invasive cardiac output monitoring has improved our understanding of the many pathophysiological mechanisms involved. Crystalloid prehydration (or preload) regimens have failed to have any significant impact on prevention of spinal hypotension, although some benefit of use of either crystalloid or colloid coloading has been demonstrated. Vasopressors remain the mainstay of treatment for both prevention and management of spinal hypotension. Increasing evidence suggests that the vasopressor of choice during SA for CD is phenylephrine (PE), however care should be taken to avoid maternal sinus bradycardia. When PE is administered as an infusion, maternal heart rate and blood pressure should be monitored closely, and any significant decrease in either should be promptly and aggressively treated.
\end{abstract}

Keywords Spinal anesthesia $\cdot$ Hypotension - Cesarean delivery · Fetus · Cardiac output · Vasopressors

\section{Introduction}

Hemodynamic changes during normal pregnancy are characterized by an increase in cardiac output (CO), heart

I. Mavridou · A. Stewart · R. Fernando $(\bowtie)$

Department of Anesthesia, University College London Hospitals

NHS Foundation Trust, 235 Euston Road, London NW1 2BU,

UK

e-mail: r.fernando@btinternet.com

I. Mavridou

e-mail: imavridou@hotmail.com

A. Stewart

e-mail: adistewart@aol.com rate (HR), and circulating blood volume and a reduction in systemic vascular resistance (SVR) [1]. Doppler blood flow measurements of maternal $\mathrm{CO}$ in the third trimester have revealed alterations in left ventricular diastolic function, associated with an increased HR and dilatation of the left atrium [2]. Among parturients undergoing spinal anesthesia (SA) for cesarean delivery (CD) hemodynamic changes occur as a result of aortocaval compression, the effects of the SA itself, and the usual physiological changes associated with normal pregnancy. It is, therefore, no surprise that, without adequate prophylaxis or treatment, SA is associated with maternal hypotension in $80-83 \%$ of parturients $[3,4 \cdot, 5,6]$.

Substantial research has been directed at finding the optimum way to minimize maternal hypotension during SA for CD. Inadequate hemodynamic control during SA can result in unpleasant symptoms, for example nausea and vomiting, in the mother and can have severe consequences for the fetus by directly compromising uteroplacental blood flow $[7 \cdot, 8]$. An understanding of the pathophysiological effects of SA on maternal hemodynamics has enabled us to target and correct appropriate physiological variables, and has led to significant advances in the management of spinal hypotension.

This review will focus on the mechanisms involved in spinal hypotension during CD under SA, the use of vasopressor therapy to counteract this effect, and the minimally invasive and non-invasive methods of measuring $\mathrm{CO}$ that are currently available.

Pathophysiology of Maternal Hypotension During SA for CD

Neuraxial anesthesia has become the anesthetic technique of choice for $\mathrm{CD}$, and has resulted in a reduction in 
maternal mortality $\left[9,10^{\bullet}\right]$. SA helps to avoid the risk of tracheal intubation, facilitate early bonding between mother and baby, and provide effective neuraxial postoperative analgesia, enabling quicker maternal recovery [11]. It is, however, associated with hypotension in more than $80 \%$ of parturients if not preemptively managed [12]. Spinal hypotension is commonly associated with nausea and vomiting in the mother, and in rare cases can result in cardiovascular collapse, loss of consciousness, or aspiration of gastric contents. Furthermore, prolonged maternal hypotension reduces uteroplacental blood flow, which may cause fetal acidosis, particularly in situations in which there is already fetal compromise [7•,8]. Hemodynamic control during $\mathrm{CD}$ under SA is therefore very important for the well-being of both the mother and the fetus.

Aortocaval compression predisposes the pregnant mother to decreases in both venous return (VR) and CO. During SA, there is loss of sympathetic tone and a reduction in SVR. This decrease in SVR, further reduces the VR and is associated with a reduction in the maternal $\mathrm{CO}$ and a reflex increase in HR. Therefore, both aortocaval compression and SA contribute to the reduction in maternal $\mathrm{CO}$ seen during $\mathrm{CD}[13 \bullet$, 14]. Blood pressure (BP) also falls, because mean arterial blood pressure (MAP) depends on both SVR and CO (MAP $=\mathrm{CO} \times \mathrm{SVR})$ [15].

A variety of measures to improve VR have been tried, for example placing the parturient in the left lateral position to reduce the effects of aortocaval compression, and utilizing different fluid pre and coload regimens, but all have failed to completely eliminate maternal hypotension [16•]. Tamilselvan et al. [6] and Teoh and Sia [18], have demonstrated that increasing $\mathrm{CO}$ by fluid preloading before SA does not result in a reduced incidence of spinal hypotension. A randomized controlled trial performed in our institution showed no differences in $\mathrm{CO}$ variables or hemodynamic stability between colloid and crystalloid coloading regimens [17•].

Much of the recent literature illustrates that a reduction in VR alone cannot be the only contributory factor to spinal hypotension during elective CD. Dyer et al. [19] showed that SA was associated with only modest afterload reduction, little change in $\mathrm{CO}$, and overall adequate hemodynamic stability in a group of 15 severely pre-eclamptic patients. As patients with pre-eclampsia are known to be intravascularly depleted, this would suggest that other factors, apart from a reduction in VR, are involved in the reduction in $\mathrm{CO}$ that occurs in normal pregnant patients having SA. A 2009 editorial by Sharwood-Smith and Drummond [15] supports this view. The authors concluded that if VR was the main factor, pre-eclamptic patients would be at major risk of hypotension during spinal anesthesia, because they typically have only an attenuated increase in plasma volume. They further expressed the opinion that in pre-eclampsia the damaged vascular epithelium results in persistent vasoconstriction, and improved hemodynamic stability during spinal anesthesia. In normal pregnancy, however, there is an altered response to endogenous vasopressors, for example angiotensin II, making the parturient prone to vasodilation and hypotension with SA.

After SA for CD there is a decrease in maternal BP, because of falls in both SVR and VR. Traditionally, maternal hemodynamic stability during $\mathrm{SA}$ has been assessed by non-invasive measurement of BP and HR. Recent research has used non-invasive and minimally invasive hemodynamic monitoring to study other physiological variables during SA for $\mathrm{CD}$. This has provided more accurate insight into the pathophysiology of spinal hypotension in the healthy parturient. Langesaeter et al. [20], performed invasive $\mathrm{BP}$ and continuous $\mathrm{CO}$ monitoring, by use of the LiDCOplus, during elective CD in 80 healthy women, randomized to receive either high-dose or low-dose $\mathrm{SA}$, with either intravenous phenylephrine (PE) or placebo. The onset of SA was associated with a rapid and profound drop in SVR with an initial compensatory increase in CO in all patient groups. This increase in $\mathrm{CO}$ presumably resulted from an increase in HR, because no significant changes in $\mathrm{SV}$ were seen. Dyer et al. used invasive BP and beat-to-beat $\mathrm{CO}$ monitoring with pulse waveform analysis and transthoracic bioimpedance changes during spinal anesthesia for $\mathrm{CD}$ in 40 healthy parturients and demonstrated similar results [21]. After induction of SA, there was a $36 \%$ decrease in SVR and a $25 \%$ compensatory increase in CO because of increases in both HR and stroke volume (SV) $[13 \cdot, 21]$. These studies both suggest that the fall in SVR seen with SA results in partial compensatory increases in $\mathrm{CO}$ brought about by increases in HR with or without an associated increase in SV.

A less frequent response to SA is bradycardia and a fall in $\mathrm{CO}$ associated with hypotension. This reflex effect is known as the supine hypotensive syndrome of pregnancy $[15,22,23]$, and is believed to occur as a result of vena caval obstruction or vagal reflex bradycardia associated with an inadequately filled heart, and may involve the Bezold-Jarisch reflex [15, 24, 25]. As the block height rises, reflex inhibition of the vagus nerve results in sympathectomy and bradycardia [25].

\section{Fetal Effects of Spinal Hypotension}

Animal studies under normal physiological conditions have shown that uteroplacental blood flow exceeds the oxygen requirement of fetal oxygen demand, providing a safety margin in terms of uterine flow fluctuations $[16 \bullet, 26]$. As a result, the effect of reduced utero-placental perfusion on the fetus is debatable. A 2010 retrospective review by 
Maayan-Metzger et al. [27] of 919 term singleton pregnancies undergoing elective $\mathrm{CD}$ under $\mathrm{SA}$, showed that maternal hypotension of more than 30 and $50 \%$ from baseline did not correlate with any perinatal complications. In a large epidemiological study by Laudenbach et al., however, SA was found to be associated with an increased risk of perinatal mortality in very preterm infants of 27-32 weeks' gestation. The study included all births occurring before 33 weeks gestation, and compared fetal outcomes for those delivered by CD under general anesthesia (GA) or spinal or epidural anesthesia. SA was associated with an increased risk of neonatal mortality in very preterm infants, compared with the GA and epidural groups [28]. However, this was an epidemiological study, with no information regarding strategies for hemodynamic control or vasopressor use, so one should be careful about inferring conclusions from this study.

\section{Vasopressor Effects on Maternal Pathophysiology}

To prevent unpleasant symptoms in the mother, and for the safety of both the mother and fetus, the hemodynamic changes associated with SA for CD should be treated or, better still, prevented. Use of vasopressors has become routine practice in the management of spinal hypotension. The ideal vasopressor, or combination of vasopressors, used would compensate for the progressive effects of ascending sympathetic blockade, maintain maternal cardiovascular stability, prevent nausea and vomiting, and have no adverse effects on uteroplacental blood flow or the fetus. Ephedrine (an alpha and beta adrenergic receptor agonist) was widely used for many years, because the alpha-adrenergic agonist effects of PE were thought to reduce uteroplacental blood flow by increasing SVR, with potentially deleterious effects for the fetus [29•, 30]. Recent research using minimally invasive or non-invasive $\mathrm{CO}$ measurement techniques on pregnant women has enabled us to determine the hemodynamic effects of vasopressors in more detail. As a result of this work, it is now widely accepted that the vasopressor of choice in the parturient is PE [10•, 31-34]. Vasopressors, however, have general systemic effects with potential adverse effects on other organs and the fetus. Their use and dosing should be carefully adjusted to avoid these adverse effects while maintaining maternal hemodynamic stability.

\section{Phenylephrine}

As already discussed, spinal hypotension during elective $\mathrm{CD}$ is associated with a reduction in SVR and a compensatory increase in $\mathrm{CO}$ mediated by an increase in HR and stroke volume. On the basis of this pathophysiological mechanism, PE, a rapidly acting alpha-adrenergic agonist, would seem to be the vasopressor of choice because it counteracts the drop in SVR and thereby restores baseline hemodynamics.

Low doses of PE increase VR and CO, by causing an increase in splanchnic venous tone, in term parturients with an expanded blood volume [16•, 35]. Higher doses of PE, however, cause a baroreceptor-mediated drop in HR, dilatation of the splanchnic circulation, diversion of blood to the splanchnic vessels, and a decrease in VR [36]. This would suggest that PE may be more effective and beneficial when used as a low-dose infusion, rather than as a bolus. Allen et al. recently studied four fixed-rate infusion regimens of PE for hemodynamic support during SA for CD. PE 25 and $50 \mu \mathrm{g} / \mathrm{min}$ administered as a prophylactic fixed rate infusion provided greater maternal hemodynamic stability than PE 75 and $100 \mu \mathrm{g} / \mathrm{min}$ [37].

Stewart et al. performed a randomized double-blind study of 75 women undergoing elective CD under SA in our institution, investigating the dose-dependent effects of PE. Patients were randomly allocated to receive one of three PE infusion regimens, 25,50 , or $100 \mu \mathrm{g} / \mathrm{min}$, titrated to maintain their SBP at or above $80 \%$ of baseline. We showed that higher doses of PE (50 and $100 \mu \mathrm{g} / \mathrm{min})$ are associated with significant dose-dependent reductions in both maternal HR and $\mathrm{CO}$ [10•]. These findings are in keeping with previous studies by Langesaeter et al. [20] and Dyer et al. [21], which also found a reduction in CO with PE infusion. The study performed by Langesaeter et al. [20] questioned the routine use of higher doses of PE. In an attempt to maintain BP at baseline levels, PE may also reduce $\mathrm{CO}$ by reducing stroke volume, in response to an increase in SVR. This effect is demonstrable after bolus administration of PE [21] and was not demonstrated when using PE in the form of an infusion [10•].

Robson et al. [38] suggested that CO, rather than BP, correlated more closely with uteroplacental blood flow. Uterine blood flow, and hence oxygen supply to the fetus, is dependent on maternal $\mathrm{CO}$. As the fetus has little oxygen-storage capacity and is completely dependent on placental oxygen delivery, the well-being of the fetus requires maternal $\mathrm{CO}$, uterine blood flow, and maternal $\mathrm{PaO}_{2}$ to be maintained at or above normal values for pregnancy [10•, 39]. Stewart et al. showed that, despite the decrease in $\mathrm{CO}$ associated with the use of higher doses of PE, no adverse effects were observed in the fetus, as indicated by Apgar scores and by umbilical arterial and venous blood gases [10॰]. However, the study by Laudenbach et al., discussed above, clearly demonstrated an increased risk of neonatal mortality for very preterm infants associated with SA. This finding raises the question as to whether this small decrease in CO may have a detrimental effect on vulnerable, preterm, or high-risk fetuses. Therefore when performing SA for $\mathrm{CD}$, fetal oxygen delivery should be optimized, by 
maintaining maternal $\mathrm{CO}$ and $\mathrm{BP}$ at or as near to baseline as possible.

Ephedrine

Ephedrine (E), a mixed alpha and beta adrenoreceptor agonist, was previously the vasopressor of choice for treatment of spinal hypotension. Ephedrine has a more delayed pressor effect than PE, and increases both maternal HR and CO [21]. During SA it is usually not necessary to increase $\mathrm{CO}$, because there is already a compensatory increase in response to the dramatic drop in SVR [20, 21]. The delay in the pressor effects of ephedrine results in an increased incidence of maternal nausea and vomiting.

A recent editorial by Dyer and Biccard [25] discussed fetal considerations associated with use of ephedrine. Ephedrine has been shown to cross the placenta and to increase base deficit in the fetus by increasing the fetal metabolic rate [31]. Although the acidosis related to ephedrine use has not been associated with hypoxia or adverse fetal outcome, Dyer and Biccard contend that in an already compromised fetus the oxygen supply/demand ratio may be adversely affected. Furthermore, Ngan Kee et al. [40] found that ephedrine use during elective CD was associated with higher lactate and plasma catecholamine concentrations, lower umbilical arterial $\mathrm{pH}$, and a greater base deficit in the fetus compared with PE. It should be noted that the higher doses of ephedrine used in this study, and the different dosing regimens, may be associated with varying degrees of fetal acidosis.

A previous study by the same group demonstrated that during emergency $\mathrm{CD}$ there were no significant differences in $\mathrm{pH}$ and base deficit between the use of ephedrine and $\mathrm{PE}$, although umbilical cord lactate levels were found to be significantly higher after ephedrine use [41]. A more recent study by Landau et al. found that not all neonates developed acidosis when ephedrine was used, and that the effect depended on their genetic make-up. They suggested that some neonates are more sensitive to the effects of ephedrine, because of differences in their adrenaline beta- 2 receptor genotype. This would imply that even small doses of ephedrine, used to treat spinal hypotension, could result in significant neonatal acidosis in genetically susceptible fetuses [42].

Overall, there is good evidence of both fetal and maternal well-being after use of alpha adrenoreceptor agonists, for example PE, as first-line vasopressors to maintain maternal hemodynamic stability during SA for CD [25, 43•]. PE infusions are associated with lower fetal base deficit than ephedrine infusions [44], because flow in the vasodilated uteroplacental circulation is systemic pressure-dependent and the uterine artery is relatively insensitive to alpha agonists [25]. So from a fetal perspective $\mathrm{PE}$ is associated with a higher $\mathrm{pH}$ and lower base deficit. From a maternal perspective it is associated with a rapid rise in SVR and restoration of $\mathrm{HR}, \mathrm{CO}$, and $\mathrm{BP}$ to baseline levels.

\section{Methods of CO Monitoring}

In daily practice, we use maternal vital signs as a surrogate for CO estimation. Traditionally, BP has been believed to be the most important variable to maintain as close to baseline as possible during CD under SA. Recent research studies, however, have revealed that HR may be a better surrogate marker for $\mathrm{CO}$ estimation. Continuous measurement of $\mathrm{CO}$ is not performed routinely during $\mathrm{CD}$, but should be considered in the management of high-risk parturients. In the awake pregnant population, $\mathrm{CO}$ measurement is usually in the form of non-invasive or minimally invasive techniques. When CO monitoring is not indicated, SBP should be maintained at or near to baseline by lowdose PE infusion, and HR should be used as a surrogate marker for maternal CO. Significant reductions in maternal HR may not be clinically as important in cases when there is a term healthy fetus, but should be promptly treated in situations when there is a preterm or compromised fetus.

Armstrong et al. [45•] provides a more in depth description of all non-invasive and minimally invasive methods of $\mathrm{CO}$ monitoring. A brief outline of the techniques currently available is given below (Tables 1, 2, 3).

\section{Non-invasive Techniques}

These techniques are based on Doppler velocimetry using ultrasound of aortic blood flow or on measurement of electrical resistance changes induced by vascular flow [45•].

\section{Transthoracic and Transesophageal Echocardiography}

Transthoracic (TTE) and transesophageal echocardiography (TEE) enable assessment of hemodynamic variables and cardiac structures; they can also be used to measure valvular and ventricular wall thickness and detect wall motion abnormalities. Use of TEE for diagnosis and management of high-risk cardiac conditions in pregnancy, including cardiomyopathy, and pulmonary and amniotic fluid embolism, has been well described; however, it requires deep sedation or general anesthesia, and is therefore not clinically applicable for the awake parturient [45•, 46-51]. Because TTE is non-invasive, feasible for an awake parturient, and useful for different diagnostic conditions and for assessing response to treatment, the popularity of TTE in obstetric anesthesia is increasing. Dennis et al. [52], have described the rapid obstetric screening 
Table 1 Studies and case reports utilizing transthoracic and transesophageal echocardiography in obstetric anesthesia

\begin{tabular}{|c|c|c|c|}
\hline Ref. & $\begin{array}{l}\text { Method of } \\
\text { CO } \\
\text { assessment }\end{array}$ & Study groups & Outcome \\
\hline $\begin{array}{l}\text { Degani } \\
\text { et al. } \\
{[68]}\end{array}$ & TTE & $\begin{array}{l}18 \text { hypertensive } \\
14 \text { normotensive }\end{array}$ & $\begin{array}{l}\text { Increased cardiac contractility secondary to an increase in } \\
\text { PVR in subjects with pregnancy-induced hypertension }\end{array}$ \\
\hline $\begin{array}{l}\text { Kuzniar } \\
\text { et al. } \\
\text { [69] }\end{array}$ & TTE & $\begin{array}{l}19 \text { pre-eclamptic } \\
9 \text { hypertensive } \\
19 \text { normotensive }\end{array}$ & $\begin{array}{l}\text { Patients with pre-eclampsia had lower HR, SV, and cardiac } \\
\text { index (CI) }\end{array}$ \\
\hline $\begin{array}{l}\text { Dennis } \\
\text { et al. } \\
\text { [70] }\end{array}$ & TTE & $\begin{array}{l}30 \text { healthy pregnant patients studied in three } \\
\text { positions }\end{array}$ & $\begin{array}{l}\text { A reduction in } \mathrm{CO} \text { was observed in the left lateral } \\
10 \text {-degree head-down position because of a reduction in } \\
\mathrm{SV}\end{array}$ \\
\hline $\begin{array}{l}\text { Dennis } \\
\text { et al. } \\
\text { [71] }\end{array}$ & TTE & $\begin{array}{l}40 \text { healthy } \\
40 \text { pre-eclamptic }\end{array}$ & $\begin{array}{l}\text { Increased CO secondary to an increase in SV and diastolic } \\
\text { dysfunction observed in the pre-eclampsia group }\end{array}$ \\
\hline $\begin{array}{l}\text { Singh } \\
\text { et al. } \\
{[46]}\end{array}$ & TEE & $\begin{array}{l}\text { Case report of a parturient with Marfan's syndrome } \\
\text { undergoing CD under GA }\end{array}$ & TEE was used to assess the aortic root intra-operatively \\
\hline $\begin{array}{l}\text { Watanabe } \\
\text { et al. } \\
\text { [49] }\end{array}$ & TEE & $\begin{array}{l}\text { Case report of a patient with pulmonary } \\
\text { hypertension undergoing CD under GA }\end{array}$ & $\begin{array}{l}\text { TEE was used to evaluate right ventricular filling intra- } \\
\text { operatively }\end{array}$ \\
\hline $\begin{array}{l}\text { Lee et al. } \\
{[50]}\end{array}$ & TEE & $\begin{array}{l}\text { Case report of a patient with paradoxical amniotic } \\
\text { fluid embolus (AFE) and cardiovascular collapse }\end{array}$ & $\begin{array}{l}\text { TEE was used during the emergency CD in the diagnosis } \\
\text { and surgical management of AFE }\end{array}$ \\
\hline
\end{tabular}

TTE transthoracic echo, $P V R$ peripheral vascular resistance, $H R$ heart rate, $C I$ cardiac index, $C O$ cardiac output, $L$ left, $S V$ stroke volume, $C D$ cesarean delivery, $A F E$ amniotic fluid embolus

echocardiography (ROSE) scan, and its application in the clinical setting. The ROSE scan enables rapid and focused TTE examination in the setting of unpredictable and lifethreatening obstetric emergencies. It is an acceptable and applicable bedside test, performed in the left lateral position, enabling comfortable and concise examination in the emergency setting. Parasternal and apical maternal cardiac views are obtained to assess contractility and volume status, aiding diagnosis and response to therapy. Right heart function and relative size are also assessed, which are particularly helpful if embolism is suspected. It also provides rapid fetal heart assessment. These abbreviated techniques can be taught to, and practiced by, clinicians, although they do not replace the formal qualitative TTE that can be performed electively at a later stage [52].

\section{Doppler Velocimetry}

This method uses the Doppler frequency shift produced as an ultrasound beam is reflected by moving red cells. This frequency shift is proportional to the blood flow velocity. Doppler ultrasound measurements of ascending aortic blood velocity have been shown to enable accurate noninvasive measurement of $\mathrm{CO}$, which has been validated in pregnancy [44, 53-55]. Doppler velocimetry can be used for $\mathrm{CO}$ measurement in the form of transesophageal or suprasternal aortic Doppler velocimetry.

\section{Transthoracic and Whole-Body Electrical Bioimpedance}

Bioimpedance techniques detect electrical resistances across the thorax or whole body, induced by vascular flow during the cardiac cycle. $\mathrm{CO}$ is continuously estimated from signal variations. Bioimpedance, however, is affected by other factors, including pulmonary edema, patient position, and diathermy rendering it impractical for use in patients undergoing CD. There are currently few data supporting the reliability of these devices for the pregnant population $[45 \bullet, 56]$.

\section{Bioreactance and Electrical Velocimetry}

This technique was developed in an attempt to overcome the problems associated with bioimpedance. Bioreactance and electrical velocimetry involve the analysis of phase shifts of an oscillating current as it traverses the thorax. Few publications exist on the use of these methods for parturients, and so further research is required before its routine use can be recommended [45•, 57, 58]. Doherty et al. assessed hemodynamic changes during elective $C D$ under SA by use of a non-invasive $\mathrm{CO}$ monitor based on bioreactance. They found that, despite maintaining maternal BP at baseline with PE boluses, bioreactance revealed significant hemodynamic fluctuations [58]. 
Table 2 Studies using Doppler velocimetry to evaluate CO in obstetric anesthesia

\begin{tabular}{|c|c|c|c|c|c|c|c|}
\hline Ref. & Methods & Groups & $N$ & Spinal drugs & Fluids & VP & Outcome \\
\hline $\begin{array}{l}\text { Stewart et al. } \\
{\left[10^{\bullet}\right]}\end{array}$ & $\begin{array}{l}\text { Suprasternal } \\
\text { Doppler } \\
\text { VP study }\end{array}$ & $\begin{array}{l}\text { Healthy } \\
\text { parturients } \\
\text { PE } \\
25 \mu \mathrm{g} / \mathrm{min} \\
50 \mu \mathrm{g} / \mathrm{min} \\
100 \mu \mathrm{g} / \mathrm{min}\end{array}$ & $\begin{array}{l}25 \\
25 \\
25\end{array}$ & $\begin{array}{l}\text { Bup } 11 \mathrm{mg}- \\
15 \mu \mathrm{g} \text { fent }\end{array}$ & $500 \mathrm{ml} \mathrm{LR}$ & $\begin{array}{l}\mathrm{SBP}>80 \% \\
\text { baseline }\end{array}$ & $\begin{array}{l}\text { Dose-dependent reduction in } \\
\mathrm{CO} \text { and } \mathrm{HR} \text { with increasing } \\
\text { concentration of PE }\end{array}$ \\
\hline $\begin{array}{l}\text { Tamilselvan } \\
\text { et al. [6] }\end{array}$ & $\begin{array}{l}\text { Suprasternal } \\
\text { Doppler } \\
\text { Preload study }\end{array}$ & $\begin{array}{l}\text { Healthy } \\
\text { 1.5 L LR } \\
0.5 \text { L HES } \\
1.0 \text { L HES }\end{array}$ & $\begin{array}{l}60 \\
20 \\
20 \\
20\end{array}$ & $\begin{array}{l}\text { Bup } 11 \mathrm{mg}- \\
15 \mu \mathrm{g} \text { fent }\end{array}$ & $\begin{array}{l}\text { Cryst or } \\
\text { colloid } \\
\text { preload }\end{array}$ & $\begin{array}{l}\text { E bolus to maintain } \\
\text { SBP }>80 \% \\
\text { baseline }\end{array}$ & $\begin{array}{l}\text { Preload increases } \mathrm{CO} \text {, however } \\
\text { hypotension still occurs }\end{array}$ \\
\hline $\begin{array}{l}\text { McDonald } \\
\text { et al. }[17 \bullet]\end{array}$ & $\begin{array}{l}\text { Suprasternal } \\
\text { Doppler } \\
\text { Coload study }\end{array}$ & $\begin{array}{l}\text { Healthy } \\
\text { 1.0 L LR } \\
\text { 1.0 L HES }\end{array}$ & $\begin{array}{l}60 \\
30 \\
30\end{array}$ & $\begin{array}{l}\text { Bup } 11 \mathrm{mg}- \\
15 \mu \mathrm{g} \text { fent }\end{array}$ & $\begin{array}{l}\text { Cryst or } \\
\text { colloid } \\
\text { coload }\end{array}$ & $\begin{array}{l}\text { PE inf to maintain } \\
\text { SBP }>80 \% \\
\text { baseline }\end{array}$ & $\begin{array}{l}\text { No differences in } \\
\text { hemodynamic stability or VP } \\
\text { requirements. No advantage } \\
\text { of colloid over crystalloid }\end{array}$ \\
\hline $\begin{array}{l}\text { Teoh and Sia } \\
\text { [18] }\end{array}$ & $\begin{array}{l}\text { Suprasternal } \\
\text { Doppler } \\
\text { Preload vs. } \\
\text { coload } \\
\text { study }\end{array}$ & $\begin{array}{l}\text { Healthy } \\
\text { Preload } \\
15 \mathrm{ml} / \mathrm{kg} \\
\mathrm{HES} \\
\text { Coload } \\
15 \mathrm{ml} / \mathrm{kg} \\
\mathrm{HES}\end{array}$ & $\begin{array}{l}40 \\
20\end{array}$ & $\begin{array}{l}\text { Bup } 10 \mathrm{mg}- \\
\text { morph } 100 \mu \mathrm{g}\end{array}$ & $\begin{array}{l}\text { Preload or } \\
\text { coload }\end{array}$ & $\begin{array}{l}\text { PE bolus to maintain } \\
\text { SBP } 90-100 \% \\
\text { baseline }\end{array}$ & $\begin{array}{l}\text { Preload significantly increased } \\
\text { maternal CO for first } 5 \text { min } \\
\text { after SA, compared to coload }\end{array}$ \\
\hline $\begin{array}{l}\text { Armstrong } \\
\text { et al. [72] }\end{array}$ & $\begin{array}{l}\text { Suprasternal } \\
\text { Doppler } \\
\text { Position study }\end{array}$ & $\begin{array}{l}\text { Healthy } \\
\text { Left lateral } \\
\text { Supine tilt } \\
\text { Sitting }\end{array}$ & 25 & N/A & N/A & N/A & $\begin{array}{l}\text { Maternal SV index, HR, and } \\
\text { SBP are higher in the lateral } \\
\text { position compared with the } \\
\text { sitting and supine tilted } \\
\text { positions }\end{array}$ \\
\hline
\end{tabular}

$N$ number studied, $V P$ vasopressor, $P E$ phenylephrine, $L R$ lactated Ringer's, HES hydroxyethyl starch, Bup bupivacaine, fent fentanyl, cryst crystalloid, inf infusion, $S B P$ systolic blood pressure, $C O$ cardiac output, morph morphine, $S A$ spinal anesthesia, $S V$ stroke volume, $H R$ heart rate

Modelflow and Nexfin CO-trek

Modelflow uses finger arterial pressure to calculate the aortic flow waveform. By use of appropriate software it can obtain limited hemodynamic data from the arterial waveform. It has been investigated in pregnancy but found to consistently underestimate stroke volume [45•, 59].

Nexfin CO-trek continually measures BP by use of a cuff around a finger. Pulse contour analysis can be used to calculate CO.

A recent study comparing the two methods for 25 awake patients after coronary artery bypass graft surgery found a close correlation between Nexfin CO-trek measurements of $\mathrm{CO}$ and thermodilution methods of $\mathrm{CO}$ measurement, whereas Modelflow readings varied significantly [60].

Minimally Invasive Techniques

Minimally invasive $\mathrm{CO}$ measurement methods include pulsecontour waveform analysis and pulse-dye densitometry.
Pulse Contour Waveform Analysis

This method uses the arterial waveform derived from an invasive arterial line to predict vascular flow. The two commonly used devices are the LiDCO and PiCCO systems. The LiDCO system is based on the lithium dilution method whereas the PiCCO system is based on transpulmonary thermodilution. These methods provide continuous real time data and the algorithms used are precise and reliable in following changes in CO [45•,61]. Pulse contour studies have been well studied and validated [62-64]. Two LiDCO systems currently in clinical use: the LiDCOplus system runs two proprietary algorithms: a continuous arterial waveform analysis system (PulseCO) coupled to a single point lithium indicator dilution calibration system (LiDCO). PulseCO uses an algorithm based on patient height, weight, gender, and age to estimate arterial compliance. The PulseCO algorithm derives SV from arterial pressure changes over time.

The LiDCOrapid system uses the PulseCO algorithm to derive SV and HR from the BP waveform. The algorithm 
Table 3 Studies using electrical resistance and pulse contour waveform analysis to evaluate CO in obstetric anesthesia

\begin{tabular}{|c|c|c|c|c|c|c|c|}
\hline Ref. & Method used & Groups studied & $N$ & Spinal drugs & $\begin{array}{l}\text { Fluid } \\
\text { protocol }\end{array}$ & $\begin{array}{l}\mathrm{BP} / \text { drug } \\
\text { protocol }\end{array}$ & Outcome \\
\hline $\begin{array}{l}\text { Dyer et al. } \\
{[21]}\end{array}$ & $\begin{array}{l}\text { Transthoracic } \\
\text { bioimpedance } \\
\text { LiDCO } \\
\text { VP study }\end{array}$ & $\begin{array}{l}\text { Healthy } \\
\text { PE group } \\
\text { E Group }\end{array}$ & $\begin{array}{l}40 \\
20 \\
20\end{array}$ & $\begin{array}{l}\text { Bup } 10 \mathrm{mg}- \\
\text { fent } 10 \mu \mathrm{g}\end{array}$ & $\begin{array}{l}20 \mathrm{ml} / \mathrm{kg} \\
\quad \text { coload } \\
\mathrm{LR}\end{array}$ & $\begin{array}{l}\text { PE or E bolus } \\
\text { to maintain } \\
\mathrm{SBP}>80 \% \\
\text { baseline } \\
\text { Oxytocin } \\
2.5 \mathrm{IU} \pm \mathrm{PE} \\
80 \mu \mathrm{g}\end{array}$ & $\begin{array}{l}\text { PE reduces } \mathrm{CO} \text { which correlated } \\
\text { with a fall in } \mathrm{HR} \\
\text { Co-administration of PE with } \\
\text { oxytocin counteracts the } \\
\text { vasodilatory effects of oxytocin }\end{array}$ \\
\hline $\begin{array}{l}\text { Dyer et al. } \\
\text { [19] }\end{array}$ & LiDCO & $\begin{array}{l}\text { Severe pre- } \\
\text { eclampsia }\end{array}$ & 15 & $\begin{array}{l}\text { Bup } 10 \mathrm{mg}- \\
\text { fent } 10 \mu \mathrm{g}\end{array}$ & $\begin{array}{l}10 \mathrm{ml} / \mathrm{kg} \\
\mathrm{LR} \\
\text { coload }\end{array}$ & $\begin{array}{l}\mathrm{PE} \text { bolus to } \\
\text { maintain } \\
\mathrm{BP}>80 \% \\
\text { baseline }\end{array}$ & $\begin{array}{l}\text { Insignificant reduction in } \mathrm{CO} \\
\text { after SA in patients with pre- } \\
\text { eclampsia } \\
\text { Oxytocin causes hypotension, } \\
\text { tachycardia and an increase in } \\
\text { CO }\end{array}$ \\
\hline $\begin{array}{r}\text { Langesaeter } \\
\text { et al. [20] }\end{array}$ & $\begin{array}{l}\text { LiDCO } \\
\text { Spinal dosing } \\
\text { and VP study }\end{array}$ & $\begin{array}{l}\text { Healthy } \\
7 \text { mg Bup }+ \text { PE } \\
7 \text { mg Bup }- \text { PE } \\
10 \text { mg Bup }+ \text { PE } \\
10 \text { mg Bup }- \text { PE }\end{array}$ & $\begin{array}{l}10 \\
10 \\
10 \\
10\end{array}$ & $\begin{array}{l}\text { Bup } 7 \mathrm{mg} \text { or } \\
10 \mathrm{mg}+4 \mu \mathrm{g} \\
\text { sufentanil }\end{array}$ & $\begin{array}{l}750 \mathrm{ml} \\
\text { saline } \\
\text { coload }\end{array}$ & $\begin{array}{l} \pm P E \text { infusion } \\
0.25 \mu \mathrm{g} / \mathrm{kg} / \\
\min \end{array}$ & $\begin{array}{l}\text { Low-dose bupivacaine with the } \\
\text { PE infusion conferred the best } \\
\text { hemodynamic stability after SA }\end{array}$ \\
\hline $\begin{array}{r}\text { Langesaeter } \\
\text { et al. [73] }\end{array}$ & LiDCO & $\begin{array}{r}\text { Severe pre- } \\
\text { eclampsia }\end{array}$ & 18 & $\begin{array}{l}\text { According to } \\
\text { height/weight/ } \\
\text { gestation }\end{array}$ & $\begin{array}{c}\text { Cautious } \\
\text { coload }\end{array}$ & $5 \mathrm{IU}$ oxytocin & $\begin{array}{l}\text { Increase in HR and a fall in SVR } \\
\text { and BP with oxytocin, oxytocin } \\
\text { should be used with caution in } \\
\text { severe pre-eclampsia }\end{array}$ \\
\hline
\end{tabular}

$N$ number studied, $B P$ blood pressure, $V P$ vasopressor, $P E$ phenylephrine, $E$ ephedrine, $L R$ lactated Ringer's, $S B P$ systolic blood pressure, $C O$ cardiac output, $H R$ heart rate, Bup bupivacaine, fent fentanyl, $S A$ spinal anesthesia, $S V R$ systemic vascular resistance

converts BP to volume, to account for aortic compliance and capacitance.

Although the Flo Trac-Vigileo is the newest of the arterial pulse contour devices, it has been extensively investigated and validated in more than 20 studies [45•, 56]. It uses statistical analysis of 20-s windows of radial artery pressure waveforms together with estimates for compliance; it also incorporates patient demographics into its calculations [59]. Compared with other methods this device has the limitation that it does not provide continuous real-time data; it does, however, have the advantage that it has self-calibrating software. Therefore, this method of measurement may not be suitable for the rapid hemodynamic fluctuations that occur during $\mathrm{CD}$ or major obstetric hemorrhage, because of concerns regarding its reliability during changes in peripheral vascular resistance [65].

\section{Pulsed Dye Densitometry}

This technique enables intermittent $\mathrm{CO}$ measurement on the basis of transpulmonary dye dilution using transcutaneous signal detection adapted from pulse oximetry [45*]. $\mathrm{CO}$ is calculated from the dye-dilution curve. The technique is subject to interference from several sources, including vasoconstriction and interstitial edema. As a result, validation techniques have revealed only moderate agreement with thermodilution techniques [45•, 66, 67]. In addition, because of concerns about the effects of maternal administration of indocyanine green dye on the fetus, this method cannot currently be recommended for use in obstetric practice.

\section{Conclusion}

SA is the most widely used method of anesthesia for $\mathrm{CD}$. The typical response to $\mathrm{SA}$ for $\mathrm{CD}$ is hypotension and an increase in maternal HR. Recent research using minimally invasive and non-invasive $\mathrm{CO}$ monitoring has shown that these changes are a result of the dramatic decrease in SVR seen with SA and a compensatory increase in $\mathrm{CO}$. As a result, we are now in a better position to target our management of spinal hypotension. However, use of these CO-monitoring techniques is the exception rather than routine and may be best suited to particularly high-risk parturients. $\mathrm{CO}$ outputmonitoring devices need further formal validation before their use in pregnancy can be recommended.

Maternal positioning to reduce aortocaval compression and fluid co-hydration continues to be routine practice, but has not been shown to be sufficient to prevent or relieve spinal hypotension. This is because spinal hypotension is 
not purely a consequence of reduction in VR, as previously believed. Without prophylactic management or timely treatment, more than $80 \%$ of parturients will develop spinal hypotension, leading to unpleasant maternal effects, for example nausea and vomiting and, in more severe cases, cardiovascular collapse, unconsciousness, and aspiration of gastric contents. Spinal hypotension reduces uteroplacental blood flow, and this may have an adverse effect on fetal well-being, particularly if the fetus is preterm or already compromised. Spinal hypotension should therefore be prevented, and treated as soon as it occurs.

Increasing evidence suggests the most appropriate firstline vasopressor for treatment of spinal hypotension is an alpha adrenoreceptor agonist, for example PE, which rapidly increases SVR and restores BP to baseline. It has become routine practice to use PE prophylactically as an infusion; however, care should be taken to avoid maternal sinus bradycardia, because this is likely to be indicative of a clinically significant decrease in CO. Recent research supports the view that $\mathrm{HR}$, rather than $\mathrm{BP}$, as originally believed, should be used as a surrogate marker for $\mathrm{CO}$.

\section{Compliance with Ethics Guidelines}

Conflict of Interest Ioanna Mavridou, Adrienne Stewart, and Roshan Fernando declare that they have no conflict of interest.

Human and Animal Rights and Informed Consent This article does not contain any studies with human or animal subjects performed by any of the authors.

\section{References}

Papers of particular interest, published recently, have been highlighted as:

- Of importance

1. Klein $\mathrm{HH}$, Pich S. Cardiovascular changes during pregnancy. Herz. 2003;28(3):173-4.

2. Sadaniantz A, Kocheril AG, Emaus SP, et al. Cardiovascular changes in pregnancy evaluated by two-dimensional and Doppler echocardiography. J Am Soc Echocardiogr. 1992;5(3):253-8.

3. Klöhr S, Roth R, Hofmann T, et al. Definitions of hypotension after spinal anaesthesia for caesarean section: literature search and application to parturients. Acta Anaesthesiol Scand. 2010;54:909-21.

4. - Cooper DW. Caesarean delivery vasopressor management. Curr Opin Anaesthesiol. 2012;25(3):300-8. This review assesses the maternal and fetal effects of vasopressor administration during SA for CD and concludes that phenylephrine is the vasopressor of choice for preventing maternal hypotension and nausea. They also suggest the need for developing phenylephrine regimens that can be used with NIBP cycling less frequently than every 1 minute.

5. Rout CC, Rocke DA, Levin J, Gouws E, Reddy D. A reevaluation of the role of crystalloid preload in the prevention of hypotension associated with spinal anesthesia for elective caesarean section. Anesthesiology. 1993;79:262-9.

6. Tamilselvan P, Fernando R, Bray J, Sodhi M, Columb M. The effects of crystalloid and colloid preload on cardiac output in the parturient undergoing planned cesarean delivery under spinal anesthesia: a randomized trial. Anesth Analg. 2009;109(6):1916-21.

7. - Mercier FJ. Cesarean delivery fluid management. Curr Opin Anaesthesiol. 2012;25(3):286-91. This review aims to guide the optimal fluid management to prevent hypotension during $C D$ under SA. The authors suggest combining prophylactic vasopressor management with either hydroxyethyl starch co- or preloading or crystalloid coloading.

8. Laudenbach V, Mercier FJ, Rozé JC, et al. Anaesthesia mode for caesarean section and mortality in very preterm infants: an epidemiologic study in the EPIPAGE cohort. Int J Obstet Anesth. 2009;18:142-9.

9. Palmer SK. Anaesthesia care for obstetric patients in the United States. In: Reynolds F, editor. Regional analgesia in obstetrics: a millennium update. London: Springer; 2000. p. 3-10.

10. - Stewart A, Fernando R, McDonald S, et al. The dose-dependent effects of phenylephrine for elective cesarean delivery under spinal anesthesia. Anesth Analg. 2010;111:1230-7. This study compares the effects of three different phenylephrine infusion regimens on CO using a suprasternal Doppler technique, demonstrating that a high infusion rate of phenylephrine reduces hypotension but has a negative effect on CO.

11. Havas F, Orhan Sungur M, Yenigün Y, Karadeniz M, Kiliç M, Özkan Seyhan T. Spinal anesthesia for elective cesarean section is associated with shorter hospital stay compared to general anesthesia. Agriculture. 2013;25:55-63.

12. Saravanan S, Kocarev M, Wilson RC, et al. Equivalent dose of ephedrine and phenylephrine in the prevention of postspinal hypotension in caesarean section. Br J Anaesth. 2006; 96:95-9.

13. - Langesæter E, Dyer RA. Maternal haemodynamic changes during spinal anaesthesia for caesarean section. Curr Opin Anaesthesiol. 2011;24(3):242-8. This review suggests a physiological approach for the prevention and treatment of haemodynamic instability during $S A$ for $C D$. Since the most frequent response to $S A$ is a decrease in SVR with partial compensation in stroke volume and $\mathrm{CO}$, the authors suggest early phenylephrine administration, using $H R$ as a surrogate for $C O$.

14. Reidy J, Douglas J. Vasopressors in obstetrics. Anesthesiol Clin. 2008;26:75-88.

15. Sharwood-Smith G, Drummond GB. Hypotension in obstetric spinal anaesthesia: a lesson from preeclampsia. Br J Anaesth. 2009;102:291-4.

16. - Dyer RA, Reed AR. Spinal hypotension during elective cesarean delivery: closer to a solution. Anesth Analg. 2010;111(5):1093-5. This editorial discusses the best approach for the prevention of maternal hemodynamic instability during cesarean delivery. The authors suggest maintaining $H R$ is of primary importance and phenylephrine dosing should be guided by $H R$ response to prevent $C O$ compromise.

17. - McDonald S, Fernando R, Ashpole K, Columb M. Maternal cardiac output changes after crystalloid or colloid coload following spinal anesthesia for elective cesarean delivery: a randomized controlled trial. Anesth Analg. 2011;113:803-10. This double-blind study compared crystalloid coload versus colloid coload, with both groups receiving a prophylactic phenylephrine infusion. The maternal CO changes over a 20 minute period after SA were very similar in both groups.

18. Teoh WH, Sia AT. Colloid preload versus coload for spinal anesthesia for cesarean delivery: the effects on maternal cardiac output. Anesth Analg. 2009;108:1592-8. 
19. Dyer RA, Piercy JL, Reed AR, et al. Hemodynamic changes associated with spinal anesthesia for cesarean delivery in severe preeclampsia. Anesthesiology. 2008;108:802-11.

20. Langesaeter E, Rosseland LA, Stubhaug A. Continuous invasive blood pressure and cardiac output monitoring during cesarean delivery: a randomized, doubleblind comparison of low-dose versus high-dose spinal anesthesia with intravenous phenylephrine or placebo infusion. Anesthesiology. 2008;109:856-63.

21. Dyer RA, Reed AR, van DD, et al. Hemodynamic effects of ephedrine, phenylephrine, and the coadministration of phenylephrine with oxytocin during spinal anesthesia for elective cesarean delivery. Anesthesiology. 2009;111:753-65.

22. Kinsella SM, Lohmann G. Supine hypotensive syndrome. Obstet Gynecol. 1994;83:774-88.

23. Kinsella SM, Tuckey JP. Perioperative bradycardia and asystole: relationship to vasovagal syncope and the Bezold-Jarisch reflex. Br J Anaesth. 2001;86:859-68.

24. Dickinson CJ. Fainting precipitated by collapse-firing of venous baroreceptors. Lancet. 1993;342:970-2.

25. Dyer RA, Biccard BM. Ephedrine for spinal hypotension during elective caesarean section: the final nail in the coffin? Acta Anaesthesiol Scand. 2012;56(7):807-9.

26. Wilkening RB, Meschia G. Fetal oxygen uptake, oxygenation, and acid-base balance as a function of uterine blood flow. Am J Physiol. 1983;244:H749-55.

27. Maayan-Metzger A, Schushan-Eisen I, Todris L, et al. Maternal hypotension during elective cesarean section and short-term neonatal outcome. Am J Obstet Gynecol. 2010;202:56.

28. Laudenbach V, Mercier FJ, Rozé JC, et al. Anaesthesia mode for caesarean section and mortality in very preterm infants: an epidemiologic study in the EPIPAGE cohort. Int J Obstet Anesth. 2009;18:142-9.

29. • Veeser M, Hofmann T, Roth R, Klöhr S, Rossaint R, Heesen M. Vasopressors for the management of hypotension after spinal anesthesia for elective caesarean section. Systematic review and cumulative meta-analysis. Acta Anaesthesiol Scand. 2012;56:810-6. This review showed that phenylephrine was associated with reduced fetal acidosis, while no difference was observed between vasopressors regarding hypotension or hypertension.

30. Ralston DH, Shnider SM, DeLorimier AA. Effects of equipotent ephedrine, metaraminol, mephentermine, and methoxamine on uterine blood flow in the pregnant ewe. Anesthesiology. 1974;40:354-70.

31. Cooper DW, Carpenter M, Mowbray P, et al. Fetal and maternal effects of phenylephrine and ephedrine during spinal anesthesia for cesarean delivery. Anesthesiology. 2002;97:1582-90.

32. Lee A. Ngan Kee WD, Gin T. A quantitative, systematic review of randomized controlled trials of ephedrine versus phenylephrine for the management of hypotension during spinal anesthesia for cesarean delivery. Anesth Analg. 2002;94:920-6.

33. Lee A, Ngan Kee WD, Gin T. A dose-response meta-analysis of prophylactic intravenous ephedrine for the prevention of hypotension during spinal anesthesia for elective caesarean delivery. Anesth Analg. 2004;98:483-90.

34. Smiley RM. Burden of proof. Anesthesiology. 2009;111:470-2.

35. Gelman S. Venous function and central venous pressure: a physiologic story. Anesthesiology. 2008;108:735-48.

36. Shoukas AA, Sagawa K. Control of total systemic vascular capacity by the carotid sinus baroreceptor reflex. Circ Res. 1973;33:22-33.

37. Allen TK, George RB, White WD, et al. A double-blind, placebocontrolled trial of four fixed rate infusion regimens of phenylephrine for hemodynamic support during spinal anesthesia for caesarean delivery. Anesth Analg. 2010;111(5):1221-9.

38. Robson SC, Boys RJ, Rodeck C, Morgan B. Maternal and fetal haemodynamic effects of spinal and extradural anaesthesia for elective caesarean section. Br J Anaesth. 1992;68:54-9.
39. Ngan Kee WD. Uteroplacental blood flow. In: Chestnut DH, Polley LS, Tsen LC, Wong CA, editors. Obstetric anesthesia: principles and practice. 4th ed. Philadelphia: Elsevier; 2009. p. 37-53.

40. Ngan Kee WD, Khaw KS, Tan PE, Ng FF, Karmakar MK. Placental transfer and fetal metabolic effects of phenylephrine and ephedrine during spinal anesthesia for caesarean delivery. Anesthesiology. 2009;111:506-12.

41. Ngan Kee WD, Khaw KS, Lau TK, Ng FF, Chui K, Ng KL. Randomised double-blinded comparison of phenylephrine vs ephedrine for maintaining blood pressure during spinal anaesthesia for non-elective Caesarean section. Anaesthesia. 2008;63:1319-26.

42. Landau R, Liu SK, Blouin JL, Smiley RM, Ngan Kee WD. The effect of maternal and fetal beta2-adrenoceptor and nitric oxide synthase genotype on vasopressor requirement and fetal acidbase status during spinal anesthesia for caesarean delivery. Anesth Analg. 2011;112:1432-7.

43. - Habib AS. A review of the impact of phenylephrine administration on maternal hemodynamics and maternal and neonatal outcomes in women undergoing caesarean delivery under spinal anesthesia. Anesth Analg. 2012;114: 377-90. This review highlights the effects of phenylephrine compared with ephedrine on maternal hemodynamics and occurrence of intraoperative nausea and vomiting. The impact of the administration of phenylephrine as a bolus for the treatment of established hypotension compared with a prophylactic infusion is discussed. This article also reviews the impact of phenylephrine compared with ephedrine on uteroplacental perfusion and fetal outcomes.

44. Ngan Kee WD, Khaw KS. Vasopressors in obstetrics: what should we be using? Curr Opin Anaesthesiol. 2006;19:238-43.

45. - Armstrong S, Fernando R, Columb M. Minimally- and noninvasive assessment of maternal cardiac output: go with the flow! Int J Obstet Anesth. 2011;20(4):330-40. This review article outlines in detail all methods of minimally and non-invasive $C O$ monitoring currently available.

46. Singh SI, Brooks C, Dobkowski W. General anesthesia using remifentanil for Cesarean delivery in a parturient with Marfan's syndrome. Can J Anesth. 2008;55:526-31.

47. Smith IJ, Gillham MJ. Fulminant peripartum cardiomyopathy rescue with extracorporeal membranous oxygenation. Int J Obstet Anesth. 2009;18:186-8.

48. Crowley R, Corniea J, Chavez D, Ho JK, Mahajan A. Intraoperative diagnosis of aortic dissection in pregnancy. $\mathrm{J}$ Cardiothorac Vasc Anesth. 2010;24:116-8.

49. Watanabe K, Hoshi T, Miyabe M, Tanaka M, Mizutani T. Volume manipulation by phlebotomy for cesarean section in a patient with pulmonary hypertension. J Anesth. 2009;23:449-52.

50. Lee PH, Shulman MS, Vellayappan U, Symes JF, Olenchock SA Jr. Surgical treatment of an amniotic fluid embolism with cardiopulmonary collapse. Ann Thorac Surg. 2010;90:1694-6.

51. Hajj-Chahine J, Jayle C, Tomasi J, Corbi P. Successful surgical management of massive pulmonary embolism during the second trimester in a parturient with heparin-induced thrombocytopenia. Interact Cardiovasc Thorac Surg. 2010;11:679-81.

52. Dennis AT. Transthoracic echocardiography in obstetric anesthesia and obstetric critical illness. Int $\mathbf{J}$ Obstet Anesth. 2011;20:160-8.

53. Robson SC, Dunlop W, Moore M, Hunter S. Combined Doppler and echocardiographic measurement of cardiac output: theory and application in pregnancy. BJOG. 1987;94:1014-27.

54. Easterling TR, Carlson KL, Schmucker BC, Brateng DA, Benedetti TJ. Measurement of cardiac output in pregnancy by Doppler technique. Am J Perinatol. 1990;7:220-2.

55. Easterling TR, Watts DH, Schmucker BC, Benedetti TJ. Measurement of cardiac output during pregnancy: validation of 
Doppler technique and clinical observations in preeclampsia. Obstet Gynecol. 1987;69:845-50.

56. Critchley LA, Lee A, Ho AM. A critical review of the ability of continuous cardiac output monitors to measure trends in cardiac output. Anesth Analg. 2010;111:1180-92.

57. Ohashi Y, Ibrahim H, Furtado L, Kingdom J, Carvalho JCA. Avaliação hemodinâmica não invasiva de mulheres não grávidas, gestantes saudáveis e gestantes com prá-eclâmpsia usando biorreatância. Rev Bras Anestesiol. 2010;60:608-13.

58. Doherty A, Ohashi Y, Downey K, Carvalho JC. Non-invasive monitoring based on bioreactance reveals significant hemodynamic instability during elective cesarean delivery under spinal anesthesia. Rev Bras Anestesiol. 2011;61:320-32.

59. Carlin A, Alfirevic Z. Physiological changes of pregnancy and monitoring. Best Pract Res Clin Obstet Gynaecol. 2008;22: 801-23.

60. Bogert LW, Wesseling KH, Schraa O, et al. Pulse contour cardiac output derived from non-invasive arterial pressure in cardiovascular disease. Anaesthesia. 2010;65:1119-25.

61. Dyer RA, James MF. Maternal hemodynamic monitoring in obstetric anesthesia. Anesthesiology. 2008;109:765-7.

62. Goedje O, Hoeke K, Lichtwarck-Aschoff M, et al. Continuous cardiac output by femoral arterial thermodilution calibrated pulse contour analysis: comparison with pulmonary arterial thermodilution. Crit Care Med. 1999;27:2407-12.

63. Buhre W, Weyland A, Kazmaier S, et al. Comparison of cardiac output assessed by pulse-contour analysis and thermodilution in patients undergoing minimally invasive direct coronary artery bypass grafting. J Cardiothorac Vasc Anesth. 1999;13:437-40.

64. Jansen JR, Schreuder JJ, Mulier JP, Smith NT, Settels JJ, Wesseling KH. A comparison of cardiac output derived from the arterial pressure wave against thermodilution in cardiac surgery patients. Br J Anaesth. 2001;87:212-22.
65. Biancofiore G, Critchley LA, Lee A, et al. Evaluation of an uncalibrated arterial pulse contour cardiac output monitoring system in cirrhotic patients undergoing liver surgery. Br J Anaesth. 2009;102:47-54.

66. Hofer CK, Buhlmann S, Klaghofer R, Genoni M, Zollinger A. Pulsed dye densitometry with two different sensor types for cardiac output measurement after cardiac surgery: a comparison with the thermodilution technique. Acta Anaesthesiol Scand. 2004;48:653-7.

67. Baulig W, Bernhard EO, Bettex D, Schmidlin D, Schmid ER. Cardiac output measurement by pulse dye densitometry in cardiac surgery. Anaesthesia. 2005;60:968-73.

68. Degani S, Abinader E, Lewinsky R, et al. Maternal echocardiography in hypertensive pregnancies. Gynecol Obstet Investig. 1989;27:2-5

69. Kuzniar J, Piela A, Skret A, et al. Echocardiographic estimation of hemodynamics in hypertensive pregnancy. Am $\mathrm{J}$ Obstet Gynecol. 1982;144:430-7.

70. Dennis A, Arhanghelschi I, Simmons C, et al. Prospective observational study of serial cardiac output by transthoracic echocardiography in healthy pregnant women undergoing cesarean delivery. Int J Obstet Anesth. 2010;19:142-8.

71. Dennis A, Simmons S, Carr C, et al. Left ventricular systolic and diastolic function and structure using transthoracic echocardiography in women with untreated preeclampsia. Int J Obstet Anesth. 2010;19:S11.

72. Armstrong S, Fernando R, Columb M, Jones T. Cardiac index in term pregnant women in the sitting, lateral and supine positions: an observational, crossover study. Anesth Analg. 2011;113: $318-22$.

73. Langesaeter E, Rosseland LA, Stubhaug A. Hemodynamic effects of oxytocin in women with severe preeclampsia. Int $\mathrm{J}$ Obstet Anesth. 2011;20:26-9. 